\title{
Ryuichi Kitamura: a tribute
}

\section{April 1949-19 February 2009}

Published online: 11 April 2009

Ryuichi Kitamura, one of the Editors of Transportation since 1990, died on 19 February after a long and incredibly brave fight against cancer.

The idea that we should publish an annual Special Issue focused on Asia was Ryuichi's. His clear commitment and dedication persuaded his colleagues on the Editorial Board as well as our Publisher that this was a good idea, that the work of researchers within this dynamic region was world class, addressing some issues peculiar to its rapid economic growth, the size and density of its metropolitan areas and its political structures. The first of these Special Issues, focused on Public Transportation Systems in Asia, was published in 2006; this was followed in 2007 by one on The Rapid Motorization of Asia: Implications for the Future. Sadly, his health led to delays in the publication of this, the third Asia Special Issue. But he was determined to deliver it and worked on it through his last days. The Editors and our Publisher are all agreed that we will do our utmost to continue with this initiative of Ryuichi.

That he continued to work on this Special Issue illustrates his fortitude and optimism. Writing to me early in January, explaining why he would be missing our annual meeting, he said "I will have to very reluctantly miss the meeting ... I will stay in Japan and concentrate on getting better for the next year or so".. This followed a message a few days earlier in which he explained that he had to spend Christmas in hospital "you wouldn't believe it as I could not believe it either-another week in hospital (and no mail). I got informal release from the hospital a bit early to spend New Year at home. A brain surgery on Halloween, hospitalization for Christmas ... its been a very eventful year for me".

Earlier, following another of his many setbacks, his amazing determination came through when he wrote "one thing I found out is that once a terrible thing happens, then it is not that terrible any more. The fear of the terrible is more fearsome than the terrible themselves. Probably this applies to anybody. So, we can all be quite resilient".

Ryuichi was a remarkable man. We will be paying tribute to his tremendous contribution to our understanding of travel behaviour in a Special Issue dedicated to his work. Writing here, on behalf of all of us who have worked with him on Transportation, Editors, Publishers and the production team, in this the last of the Asia Special Issues to which Ryuichi directly contributed, I want to record our admiration for him, for his courage and for his hopefulness. We will all miss his gentleness, his wit, his sagacity and his friendship. But no one will miss him more than his family, with whom we all sympathise, most deeply.

Martin Richards Editor in Chief 